\title{
Multivariate factor analysis of detailed milk fatty acid profile: Effects of dairy system, feeding, herd, parity, and stage of lactation
}

\author{
M. Mele, ${ }^{*}$ N. P. P. Macciotta,† A. Cecchinato, $\ddagger$ G. Conte, ${ }^{*}$ S. Schiavon, $\ddagger$ and G. Bittante \\ *Dipartimento di Scienze Agrarie, Alimentari, Agro-ambientali, Università di Pisa, Via del Borghetto, 80, 56124 Pisa, Italy \\ †Dipartimento di Agraria, Sezione Scienze Zootecniche, Università di Sassari, Via de Nicola 9, 07100 Sassari, Italy \\ †Department of Agronomy, Food, Natural Resources, Animals and Environment (DAFNAE), University of Padova, Viale dell'Università 16, \\ 35020 Legnaro, Padova, Italy
}

\begin{abstract}
We investigated the potential of using multivariate factor analysis to extract metabolic information from data on the quantity and quality of milk produced under different management systems. We collected data from individual milk samples taken from 1,158 Brown Swiss cows farmed in 85 traditional or modern herds in Trento Province (Italy). Factor analysis was carried out on 47 individual fatty acids, milk yield, and 5 compositional milk traits (fat, protein, casein, and lactose contents, somatic cell score). According to a previous study on multivariate factor analysis, a variable was considered to be associated with a specific factor if the absolute value of its correlation with the factor was $\geq 0.60$. The extracted factors were representative of the following 12 groups of fatty acids or functions: de novo fatty acids, branched fatty acid-milk yield, biohydrogenation, long-chain fatty acids, desaturation, short-chain fatty acids, milk protein and fat contents, odd fatty acids, conjugated linoleic acids, linoleic acid, udder health, and vaccelenic acid. Only 5 fatty acids showed small correlations with these groups. Factor analysis suggested the existence of differences in the metabolic pathways for de novo short- and medium-chain fatty acids and $\Delta^{9}$-desaturase products. An ANOVA of factor scores highlighted significant effects of the dairy farming system (traditional or modern), season, herd/date, parity, and days in milk. Factor behavior across levels of fixed factors was consistent with current knowledge. For example, compared with cows farmed in modern herds, those in traditional herds had higher scores for branched fatty acids, which were inversely associated with milk yield; primiparous cows had lower scores than older cows for de novo fatty acids, probably due to a larger contribution of lipids mobilized from body
\end{abstract}

Received May 12, 2016.

Accepted August 8, 2016

${ }^{1}$ Corresponding author: alessio.cecchinato@unipd.it depots on milk fat yield. The statistical approach allowed us to reduce a large number of variables to a few latent factors with biological meaning and able to represent groups of fatty acids with a common origin and function. Multivariate factor analysis would therefore be a valuable tool for studying the influence of different production environments and individual animal factors on milk fatty acid composition, and for developing nutritional strategies able to manipulate the milk fatty acid profile according to consumer demand.

Key words: Brown Swiss, factor analysis, fatty acids, milk fat

\section{INTRODUCTION}

Milk fat contains more than 400 fatty acids (FA) deriving partly from mammary gland synthesis (nearly $50 \%$ ), partly from diet as affected by rumen biohydrogenation process, and from the mobilization of animal fat depots (Chilliard et al., 2000). Some FA classes, such as branched-chain FA, and cis and trans isomers of $18: 1,18: 2$, and 18:3, are related to rumen activity (Chilliard et al., 2007; Fievez et al., 2012; Shingfield et al., 2013), whereas other FA classes, such as de novo FA and, again, those with 18 carbon chains, are also related to energy metabolism (Van Haelstetal., 2008; Shingfield et al., 2013; Loften et al., 2014). Therefore, because the FA profile of a milk sample could be regarded as the cow's nutritional and metabolic footprint, analysis of variability in milk yield (MY) and the milk FA profile would allow us to make inferences about different farming or feeding systems, herds, or even factors reflecting the health status of the cows.

The technology for analyzing milk FA by gas chromatography has greatly improved over the last $20 \mathrm{yr}$, and it is now possible to routinely obtain detailed milk FA profiles composed of many individual FA, including several positional and geometric isomers of the 16:1, 18:1, 18:2, and 18:3 groups (Delmonte et al., 2012). However, interpretation of the resulting complex patterns of composition is not easy, especially when differences 
among animals are not a priori determined, as happens in experimental situations. When investigations are carried out on commercial dairy farms, large differences could be present in management practices and feeding regimens: for example, type of confinement (free stalls or tie-stalls), total amount and type of forage (silage, hay, hay and silage), type of ration (TMR or separate administration of dietary ingredients), and concentrate administration (auto-feeders or TMR). These differences may have a huge effect on FA variation, making the drawing of inferences about the metabolic status of the animals across or within production environment problematic. In these situations, information about the metabolic or feeding status of the cow could be obtained by evaluating the simultaneous variations in groups of FA rather than in individual FA.

Multivariate statistics offers several techniques able to capture the covariance structure of complex patterns of variables. Some of these techniques can summarize the relationships among many traits with a lower number of new explanatory variables, allowing for a simpler interpretation of the original multivariate system. Of particular interest with specific regard to analysis of the milk FA profile is multivariate factor analysis (MFA), where such a reduction is carried out with the aim of explaining the maximum amount of (co) variance among the original variables (Morrison, 1976). The factor theoretical model assumes that the total variance in a multivariate system can be divided into 2 components: one that is shared by all the variables and is called communality, and one that is peculiar to each variable and is called uniqueness. Thus, each of the $n$ original variables of the system is modeled as a linear combination of $p$ common factors (or latent variables) that generates communality between variables plus a specific residual (Morrison, 1976). Multivariate factor analysis has been used to analyze MY by starting from 7 original variables represented by daily MY recorded at different lactation stages and deriving 2 latent variables related to lactation peak and persistency, respectively (Macciotta et al., 2004). The MFA was also used to model milk composition (Todaro et al., 2005) and milk coagulation properties (Macciotta et al., 2012). In the case of a detailed milk FA profile, factor analysis could be a useful method for analyzing the complex pattern of correlations among FA, and for studying the mutual relationships among them. Another key output of MFA of milk FA may be the generation of a few uncorrelated synthetic variables with clear technical and biological meanings to be used as new phenotypes in further analyses.

In the present study, we carried out MFA on individual detailed milk FA compositions of a large number of milk samples from Italian Brown Swiss cows. Our aims were (1) to study the correlation patterns among FA, with a particular focus on mutual relationships among classes of FA, and (2) to generate new response variables to be used as novel phenotypes for assessing the relationships between FA profile and feeding and management systems.

\section{MATERIALS AND METHODS}

\section{Dairy Farming Systems, Herds, and Seasons}

The present study is part of the Cowability-Cowplus projects. Briefly, the study was carried out on 85 herds located in Trento Province (northeastern Italian Alps) and enrolled in the milk-recording program of the local Provincial Federation of Breeders (FPA, Trento, Italy). The herds were selected from 610 farms to represent different environments and dairy farming systems (Sturaro et al., 2009, 2013). The farming systems of the herds involved in the present study have been classified and described by Bittante et al. (2015).

Briefly, the 29 farms using the traditional dairy system were small (average 18.6 ha of cultivated land) with a small number of cows (average 28) kept tied all around year in old facilities or moved to highland pasture during summer (no samplings were performed at pasture). These cows were fed on meadow hay, mainly produced on the farm, and a small-medium amount of compound feed from the feed industry (18\% of DMI), often administered to individual stalls through an automatic device. Milking was carried out at individual stalls using the mechanical method.

The 56 farms of the modern dairy system were larger, with more cows (average 45) kept in loose housing and milked in milking parlors, and made partial or no use of summer highland pasture. The first distinction among the modern farms was the use or otherwise of TMR (TMR vs. no TMR). The no TMR farms $(\mathrm{n}=30)$ often adopted a feeding regimen similar to traditional farms but with more compound feed per cow (30\% DMI) and sometimes with the administration of silages, especially corn silage. Among the dairy farms using TMR (concentrates accounting for about $50 \%$ of DMI), there was a further distinction between those using corn silage (silage, 9 farms) and those moistening the TMR with water (water, 17 farms). The reason for this difference is the destination of the milk: European Union regulations regarding the manufacture of traditionally longripened hard cheeses (Trentingrana) with Protected Designation of Origin prohibit the administration of silages to avoid inflation of wheels during ripening (Bittante et al., 2011). 
The farms were sampled once in a calendar year (15 cows per herd, with few exceptions, balanced for parity, DIM, and MY). Herds were selected to ensure they were evenly distributed over the different dairy systems and over the 2 main seasons: April to September and October to March.

\section{Milk Sampling and Cows}

Milk samples (one per cow) were collected from 1,158 Brown Swiss cows (a maximum of 15 cows per herd) during the evening milking. The milk samples (no preservative was added) were immediately refrigerated at $4^{\circ} \mathrm{C}$ and transferred to the Cheese-Making Laboratory of the Department of Agronomy, Food, Natural Resources, Animals and Environment of the University of Padua (Legnaro, Padua, Italy). Data on the cows and herds were provided by the Superbrown Consortium of Bolzano and Trento (Italy).

\section{Milk Fatty Acid Analysis}

Fatty acid methyl esters were prepared by the direct extraction and alkali catalyzed trans-methylation procedure, previously described by Feng et al. (2004); a detailed description of the procedure is reported in Pegolo et al. (2016). Briefly, the FA composition was determined using a ThermoQuest gas chromatograph (Thermo Electron Corp., Waltham, MA) equipped with a flame-ionization detector and a high polar fusedsilica capillary column (Chrompack CP-Sil88 Varian, Middelburg, the Netherlands; $100 \mathrm{~m}, 0.25 \mathrm{~mm}$ i.d.; film thickness $0.20 \mu \mathrm{m}$ ). Individual FAME were identified by comparison with standard mixtures, pure standards, and published gas chromatography profiles. In the case of 16:1, 18:1, and 18:2 isomers, risk of peak co-elution was assessed using Ag-Ion SPE fractionation, according to Kramer et al. (2008). The gas chromatography column adopted allows a more detailed composition to be obtained, including more cis and trans isomers of $16: 1,16: 2,18: 1,18: 2$, and 18:3, providing solid phase separation techniques are combined with GC-MS analysis and the same sample is processed by 2 or more runs in GC-flame ionization detector to set different temperature gradients able to completely separate the isomers (Delmonte et al., 2012). Considering the large number of samples in this study, we preferred to carry out a single run analysis per sample by applying a temperature gradient able to separate the main 16:1, 18:1, 18:2, and 18:3 isomers. However, in the area of the chromatogram between 18:0 and 18:2 $c 9, c 12$, it was not possible to avoid co-elution of $18: 1$ isomers $t 13, t 14$, and $c 9$, and of the 18:1 $c 11$ and $t 15$ isomers (where $\boldsymbol{c}=$ cis and $t=$ trans).

A reference standard butter (BCR 164; Commission of the European Communities, Community Bureau of Reference, Brussels, Belgium) was used to estimate correction factors for the short-chain FA, as previously described by Mele et al. (2008). Inter- and intraassay coefficients of variation were also calculated using the same reference standard butter, the detection limit of the analysis being $0.001 \%$ above that of the total FA amount. Milk FA composition was expressed as grams per $100 \mathrm{~g}$ of total FA.

\section{Statistical Analysis}

MFA. The main aim of multivariate factor analysis is to explain the (co)variance of a system defined by $n$ measured traits $\left(\mathrm{y}_{1}, \ldots, \mathrm{y}_{\mathrm{n}}\right)$ by deriving a smaller number $p(p<n)$ of latent unobservable variables $\left(\mathrm{X}_{1}, \ldots\right.$, $\mathrm{X}_{\mathrm{p}}$ ), named common latent factors. Multivariate factor analysis assumes that the variance of each original variable can be decomposed into its common and unique components, named as communality and uniqueness, respectively. The factor model decomposes the covariance matrix of the measured traits (S) as follows:

$$
\mathrm{S}=\mathrm{BB}^{\prime}+\Psi
$$

where $\mathbf{B B}^{\prime}$ and $\boldsymbol{\Psi}$ are the communality and the uniqueness (co)variance matrices, respectively (Morrison, 1976).

According to the (co)variance model, the measured traits could be represented as a combination of $\mathrm{p}$ unobservable common factors (X) plus a unique variable (e) (Morrison, 1976):

$$
\begin{gathered}
\mathrm{y}_{1}=\mathrm{b}_{11} \mathrm{X}_{1}+\ldots+\mathrm{b}_{1 \mathrm{p}} \mathrm{X}_{\mathrm{p}}+\mathrm{e}_{1} \\
\mathrm{yn}=\mathrm{bn}_{1} \mathrm{X}_{1}+\ldots+\operatorname{bnp} \mathrm{X}_{\mathrm{p}}+\mathrm{e}_{\mathrm{n}},
\end{gathered}
$$

where $\mathrm{b}$ are factor loadings that express the correlation between the ith latent factor and the measured trait. Loadings are the elements of the $\mathbf{B}$ matrix of the theoretical factor variance model.

Factor analysis was carried out on the correlation matrix of 53 measured variables; that is, 47 individual FA and 6 milk production traits (MY, fat, protein, casein and lactose contents, SCS) measured in the 1,158 cows using the SAS FACTOR procedure (SAS Inst. Inc., Cary, NC). The number of factors to be extracted was based on their eigenvalue $(>1)$, their readability in terms of relationships with the original variables, and the amount of explained variance. Factor readability 
was improved through a VARIMAX rotation. According to Macciotta et al. (2015), a variable was considered associated with a specific factor if the absolute value of its loading was $\geq 0.60$.

Factor scores were calculated for each cow according to the following formula:

$$
\mathbf{x}^{\prime}=\mathbf{y}^{\prime} \times\left(\mathbf{B B}^{\prime}+\mathbf{\Psi}\right)^{-1} \times \mathbf{B},
$$

where $\mathbf{x}^{\prime}$ is the row vector of factor scores, $\mathbf{y}^{\prime}$ is the row vector of standardized (value - mean)/standard deviation) traits. Standardized instead of raw values were used because analyzed traits had different units of measurement and scale.

Mixed Model Analysis. Individual factor scores were analyzed with the following mixed linear model:

$$
\begin{gathered}
y_{i j k l m n}=\mu+{\text { dairy } \text { system }_{i}+\text { season }_{j}}+\text { herd }_{k}\left(\text { dairy system } \times \text { season }_{i j}+\text { parity }_{l}\right. \\
+ \text { DIM }_{m}+e_{i j k l m n},
\end{gathered}
$$

where $y_{i j k l m n}$ is the observed phenotype (i.e., the factor scores); $\mu$ is the overall mean; dairy system $_{i}$ is the fixed effect of the $i$ th dairy system ( $i=1$ to 4 ); season $_{j}$ is the $j$ th season ( $j=1$ April to September; $j=2$ October to March); herd ${ }_{k}\left(\right.$ dairy system $\times$ season $_{i j}$ is the random effect of the $k$ th herd $(k=1$ to 85$) \sim N\left(0, \mathbf{I} \sigma_{H}^{2}\right)$ nested within the $i$ th dairy system and $j$ th season; parity is the fixed effect of the $l$ th parity ( $l=1$ to 4 or more lactations); $D I M_{m}$ is the $m$ th 30 -d class of DIM, 11 classes; and $e_{i j k l m n}$ is the residual random error term $\sim N\left(0, \sigma_{e}^{2}\right)$. The significances of dairy system and season were tested on the error line of herd within dairy system and season, and those of parity and DIM class on the error line of the residual variance.

Orthogonal post hoc contrasts $(P<0.05)$ were built for dairy system and parity factors: (1) the traditional dairy system was compared with the modern systems; (2) within the modern systems, the no TMR herds were compared with the TMR herds; and (3) within the TMR herds, those that use silage were compared with those that use water. In addition, first, second, and third parities were each compared with greater parities.

\section{RESULTS AND DISCUSSION}

The overall pattern of milk FA composition (Table 1) consisted of 22 SFA, 14 MUFA, and 11 PUFA. The values confirmed previous reports on intensive dairy farms located in northern Italy (Borreani et al., 2013; Coppa et al., 2013): SFA accounted for almost $70 \%$ of total FA, MUFA accounted for less than 25\%, and PUFA was a minor part, accounting for less than $5 \%$. Palmitic acid (16:0), oleic acid (18:1 $c 9$ ), and linoleic acid (18:2 $c 9, t 11)$ were the main SFA, MUFA, and PUFA, respectively. The concentrations of $18: 3$ and 18:2 $c 9, t 11$ in milk reflected the exclusive use of preserved forage and diet supplementation with scant or moderate amounts of lipids derived from vegetable oils (Chilliard and Ferlay, 2004; Couvreur et al., 2006; Mele, 2009).

\section{Latent Factors of Milk Fatty Acid Composition}

The MFA was able to extract 12 latent factors from the 53 variables measured (6 milk traits and $47 \mathrm{FA}$ ), accounting for about $75 \%$ of the total variance. The factor pattern (i.e., the correlations between each factor and the original variables) was quite easy to read. In particular, a relatively small number of variables exhibited correlations $\geq 0.60$ in each factor, whereas the remainder had very low correlations (in many cases close to zero). If we examine the pattern across factors, we can see that each variable was highly correlated with only one factor and poorly with the others. This type of simple structure is an indicator of the suitability of factor model assumptions for the kind of data analyzed (Morrison, 1976). The suitability of the data set for MFA was further checked by calculating the Kaiser measure of sampling adequacy (MSA), which measures the difference between Pearson and partial correlations. In the present study, the MSA value was 0.78 , close to the empirical threshold of 0.80 that flags a data set as particularly suitable for MFA (Macciotta et al., 2012).

The first latent factor was positively associated with medium-chain SFA (8:0 to 14:0), and negatively with 17:0, 17:1 $c 9$, and 18:1 $c 9$. All the FA that exhibited positive correlations with this factor share a common metabolic origin, being de novo synthesized in the mammary gland from acetate by the FA synthase enzyme (Chilliard et al., 2000). Those with negative loadings were all related to the activity of the stearoyl Co-A desaturase enzyme (SCD) that catalyzes desaturation of the carbon chain at the $\Delta 9$ position in a large spectrum of FA (Ntambi, 1999). Therefore, the milk from animals having larger scores for factor 1 is richer in de novo synthesized FA. Milk fat fluidity is strongly affected by the relative abundance of de novo SFA and 18:1 $c 9$ produced by SCD. In fact, according to Chilliard et al. (2000), selective esterification of de novo short-chain FA (from 4 to 10 carbons) and 18:1 $c 9$ to the glycerol backbone at $s n-3$ position plays a pivotal role in the regulation of milk fat fluidity. This factor was therefore named de novo FA.

The second latent factor explained a similar amount of variance than the first factor (Tables 2 and 3). It 
Table 1. Descriptive statistics for milk production traits and individual fatty acids $(\mathrm{FA} ; \mathrm{n}=1,158)^{1}$

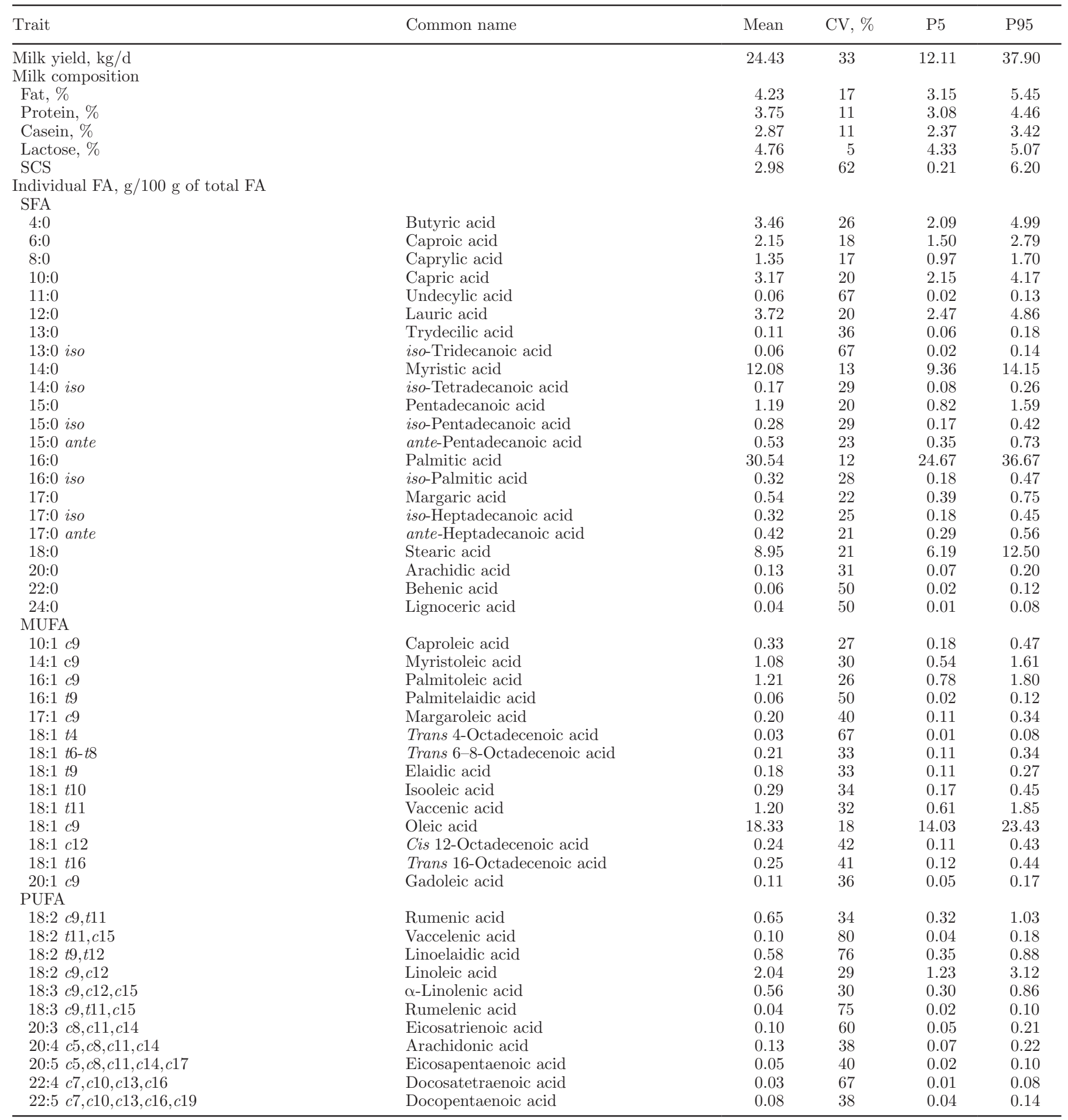

${ }^{1} \mathrm{P} 5=5$ th percentile, $\mathrm{P} 95=95$ th percentile. $c=$ cis; $t=$ trans.

was named branched FA-MY and was positively correlated with branched-chain FA and negatively with MY. Among the branched-chain FA, 17:0 iso showed a weak (0.50) association with this latent factor, possibly due to coelution with some 16:1 isomers, as also reported by Fievez et al. (2012). Branched FA are mainly produced in the rumen by cellulolytic bacteria, so their content in milk is positively related to the amount of forage 
Table 2. Rotated factor (F) pattern and proposed factor name, for F1 through F6 ${ }^{1}$

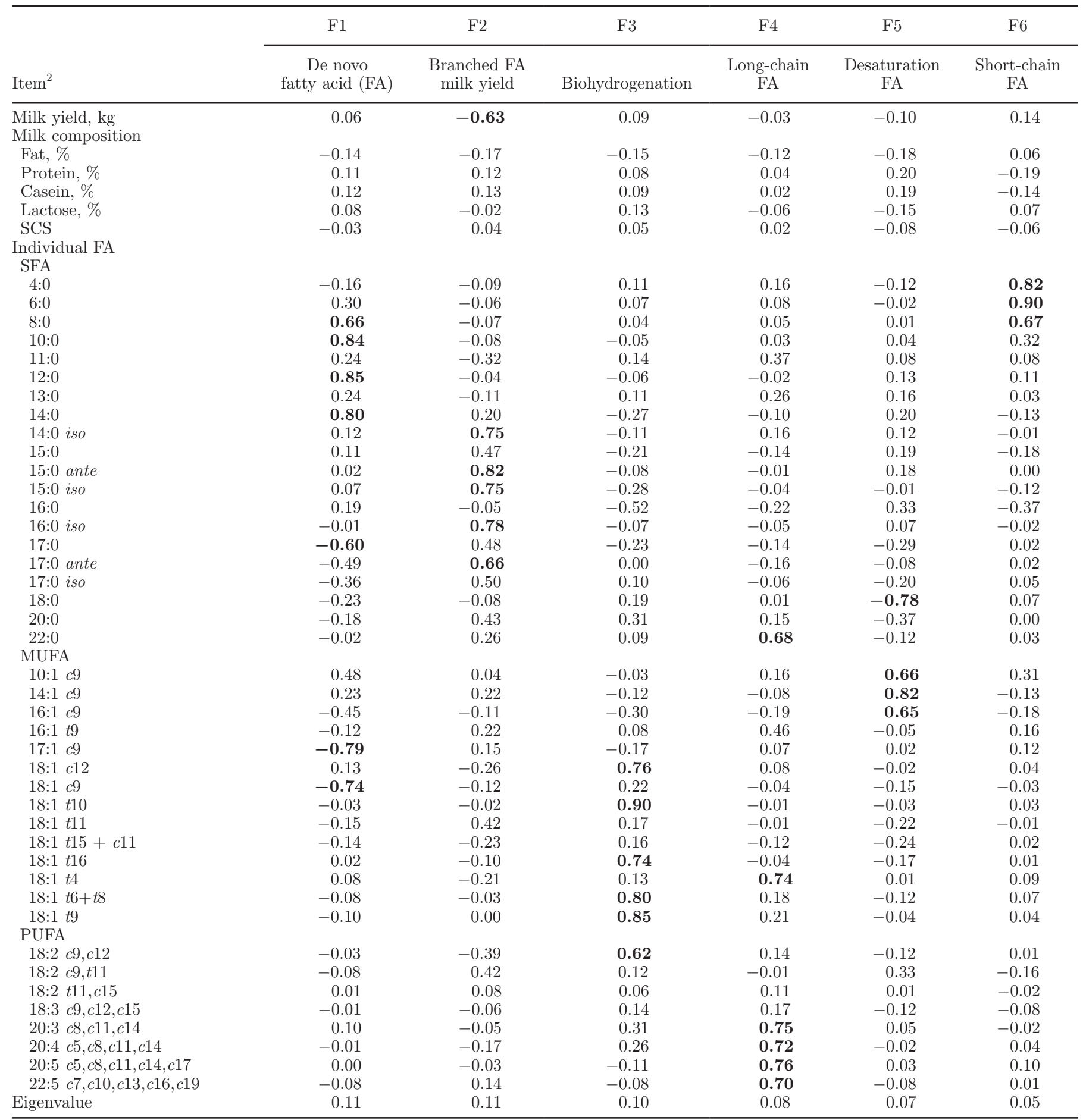

${ }^{1}$ Values above 0.6 in bold.

${ }^{2} c=$ cis; $t=$ trans.

in the diet (Vlaeminck et al., 2006). High scores for factor 2 indicate cows with low productive values fed high-forage diets.
The third latent factor was named biohydrogenation because it was positively related to linoleic acid (18:2 $c 9, c 12)$ and to some products of its rumen biohydroge- 
nation $(18: 1 c 12,18: 1 t 6-8,18: 1 t 9,18: 1 t 10$, and 18:1 $t 16)$. Vaccenic acid (18:1 t11), one of the main products of linoleic acid biohydrogenation, did not have a large loading on this factor, and was instead included in fac- tor 9. Linoleic acid $(18: 2 c 9, c 12)$ is often the main FA contained in dietary lipids and is actively biohydrogenated by rumen bacteria to stearic acid (18:0). During this process, a large spectrum of cis and trans isomers

Table 3. Rotated factor $(\mathrm{F})$ pattern, proposed factor name, and variable communality (Com) for F7 through F12

\begin{tabular}{|c|c|c|c|c|c|c|c|}
\hline \multirow[b]{2}{*}{ Item $^{2}$} & F7 & F8 & F9 & F10 & F11 & F12 & \multirow[b]{2}{*}{ Com } \\
\hline & $\begin{array}{l}\text { Milk } \\
\text { fat protein }\end{array}$ & $\begin{array}{l}\text { Odd fatty } \\
\text { acid (FA) }\end{array}$ & CLA & $\begin{array}{l}\text { Linolenic } \\
\text { acid }\end{array}$ & $\begin{array}{l}\text { Udder } \\
\text { health }\end{array}$ & $\begin{array}{c}\text { Vaccelenic } \\
\text { acid }\end{array}$ & \\
\hline Milk yield, kg & -0.41 & 0.06 & -0.14 & 0.13 & -0.11 & -0.05 & 0.66 \\
\hline \multicolumn{8}{|l|}{ Milk composition } \\
\hline Fat, $\%$ & 0.66 & 0.00 & 0.09 & -0.22 & 0.09 & 0.02 & 0.62 \\
\hline Protein, \% & 0.87 & 0.09 & -0.10 & 0.11 & 0.06 & -0.02 & 0.90 \\
\hline Casein, \% & 0.88 & 0.09 & -0.09 & 0.10 & -0.01 & -0.03 & 0.90 \\
\hline Lactose, \% & -0.12 & 0.09 & -0.01 & -0.02 & -0.73 & -0.11 & 0.63 \\
\hline SCS & 0.00 & 0.01 & 0.04 & -0.01 & 0.82 & -0.08 & 0.69 \\
\hline \multicolumn{8}{|l|}{ Individual FA } \\
\hline \multicolumn{8}{|l|}{ SFA } \\
\hline $4: 0$ & -0.17 & -0.09 & 0.03 & -0.09 & -0.07 & -0.01 & 0.81 \\
\hline $6: 0$ & -0.13 & 0.03 & -0.01 & -0.03 & -0.08 & -0.03 & 0.93 \\
\hline $8: 0$ & -0.03 & 0.10 & -0.10 & 0.07 & -0.06 & 0.02 & 0.93 \\
\hline 10:0 & 0.07 & 0.22 & -0.09 & 0.10 & -0.04 & -0.01 & 0.90 \\
\hline $11: 0$ & 0.12 & 0.66 & -0.10 & -0.01 & -0.03 & 0.01 & 0.80 \\
\hline $12: 0$ & 0.14 & 0.27 & -0.16 & 0.03 & -0.02 & 0.04 & 0.88 \\
\hline $13: 0$ & 0.12 & 0.75 & -0.07 & 0.02 & -0.04 & 0.00 & 0.76 \\
\hline $14: 0$ & -0.02 & 0.13 & -0.02 & -0.08 & -0.03 & 0.09 & 0.86 \\
\hline $14: 0$ iso & 0.01 & -0.05 & 0.25 & -0.05 & 0.00 & 0.09 & 0.70 \\
\hline $15: 0$ & 0.00 & 0.69 & -0.07 & 0.04 & -0.07 & -0.04 & 0.85 \\
\hline 15:0 ante & 0.02 & 0.14 & 0.13 & 0.05 & -0.05 & -0.14 & 0.77 \\
\hline 15:0 iso & -0.01 & -0.04 & 0.02 & 0.00 & 0.07 & 0.23 & 0.71 \\
\hline $16: 0$ & -0.14 & 0.15 & -0.03 & -0.41 & 0.03 & -0.08 & 0.82 \\
\hline 16:0 iso & 0.04 & -0.15 & 0.13 & -0.05 & -0.03 & -0.04 & 0.67 \\
\hline $17: 0$ & -0.12 & 0.24 & 0.00 & 0.07 & 0.02 & -0.05 & 0.83 \\
\hline 17:0 ante & -0.03 & 0.08 & -0.15 & 0.07 & -0.02 & -0.04 & 0.74 \\
\hline $17: 0$ iso & -0.09 & 0.03 & -0.22 & -0.06 & 0.15 & 0.03 & 0.52 \\
\hline $18: 0$ & -0.01 & -0.27 & 0.06 & 0.18 & -0.05 & -0.07 & 0.83 \\
\hline $20: 0$ & 0.00 & 0.02 & -0.16 & -0.32 & 0.00 & 0.05 & 0.60 \\
\hline $22: 0$ & -0.04 & 0.09 & 0.08 & -0.23 & 0.07 & 0.05 & 0.63 \\
\hline \multicolumn{8}{|l|}{ MUFA } \\
\hline $10: 1 c 9$ & 0.10 & 0.09 & 0.04 & 0.07 & -0.01 & -0.09 & 0.82 \\
\hline $14: 1 c 9$ & 0.15 & 0.06 & 0.01 & -0.03 & 0.02 & 0.00 & 0.83 \\
\hline $16: 1 c 9$ & 0.15 & 0.04 & -0.04 & -0.08 & 0.08 & 0.01 & 0.83 \\
\hline $16: 1$ t9 & -0.02 & 0.08 & 0.49 & -0.19 & 0.04 & 0.08 & 0.60 \\
\hline $17: 1 c 9$ & -0.01 & 0.16 & 0.03 & -0.05 & 0.04 & 0.09 & 0.73 \\
\hline $18: 1 c 12$ & 0.09 & 0.07 & -0.03 & 0.21 & -0.01 & 0.11 & 0.74 \\
\hline $18: 1 c 9$ & 0.16 & -0.29 & -0.04 & 0.25 & 0.00 & 0.01 & 0.81 \\
\hline $18: 1 t 10$ & -0.06 & 0.02 & 0.13 & 0.00 & -0.03 & 0.00 & 0.83 \\
\hline $18: 1 t 11$ & -0.15 & -0.23 & 0.68 & 0.16 & 0.05 & 0.11 & 0.86 \\
\hline $18: 1 t 15+c 11$ & -0.02 & 0.19 & 0.24 & 0.21 & 0.07 & -0.03 & 0.31 \\
\hline $18: 1 t 16$ & 0.05 & 0.01 & -0.15 & 0.20 & -0.04 & 0.08 & 0.67 \\
\hline $18: 1$ t4 & 0.01 & -0.04 & 0.15 & -0.06 & -0.09 & 0.03 & 0.66 \\
\hline $18: 1 t 6+t 8$ & -0.06 & -0.01 & 0.15 & -0.18 & 0.01 & -0.10 & 0.77 \\
\hline $18: 1$ t9 & -0.03 & -0.02 & 0.16 & -0.12 & 0.00 & 0.03 & 0.82 \\
\hline \multicolumn{8}{|l|}{ PUFA } \\
\hline $18: 2 c 9, c 12$ & 0.03 & -0.01 & -0.22 & 0.38 & 0.00 & -0.08 & 0.77 \\
\hline $18: 2 c 9, t 11$ & 0.01 & -0.22 & 0.62 & 0.26 & 0.06 & 0.06 & 0.84 \\
\hline $18: 2 t 11, c 15$ & -0.02 & -0.01 & 0.08 & 0.13 & 0.02 & 0.91 & 0.87 \\
\hline $18: 3 c 9, c 12, c 15$ & -0.01 & 0.03 & 0.10 & 0.76 & 0.01 & 0.16 & 0.68 \\
\hline $20: 3 c 8, c 11, c 14$ & 0.11 & 0.04 & -0.20 & 0.01 & 0.05 & 0.05 & 0.73 \\
\hline $20: 4 c 5, c 8, c 11, c 14$ & 0.05 & 0.04 & -0.24 & 0.12 & 0.05 & -0.01 & 0.70 \\
\hline $20: 5 c 5, c 8, c 11, c 14, c 17$ & -0.11 & 0.04 & 0.07 & 0.16 & 0.03 & 0.11 & 0.65 \\
\hline $22: 5 c 7, c 10, c 13, c 16, c 19$ & -0.04 & 0.15 & 0.10 & 0.29 & 0.01 & -0.10 & 0.65 \\
\hline Eigenvalue & 0.05 & 0.05 & 0.04 & 0.04 & 0.03 & 0.02 & \\
\hline
\end{tabular}

${ }^{1}$ Values above 0.6 in bold.

${ }^{2} c=$ cis; $t=$ trans. 
of 18:1 are produced in the rumen, including 18:1 t6-8, 18:1 t9, 18:1 t10, 18:1 t16, and 18:1 $c 12$ (Shingfield et al., 2010). Therefore, the content of these FA in milk fat would be strictly related to the amount of $18: 2 c 9, c 12$ in the diet and to the extent of rumen biohydrogenation.

Long-chain FA positively correlated with factor 4, consistently named long-chain FA. In milk fat, longchain FA are mainly contained in the phospholipid fraction, which represents less than $2 \%$ of total lipids (Jensen, 2002). They may also be produced in the mammary gland by elongation of linoleic and $\alpha$-linolenic acids of dietary origin (Bionaz and Loor, 2008). High scores in this factor may indicate a cow more efficient to promote the elongation of linoleic and $\alpha$-linolenic acid.

Latent factor 5 was named desaturation. It was positively correlated with 14:1 $c 9$ and 16:1 $c 9$, and negatively with stearic acid (18:0). The first 2 FA derive from SCD activity on the respective SFA (14:0 and 16:0). The ratios 14:1/14:0 and, to a lesser extent, 16:1/16:0 are considered a proxy of SCD activity in the mammary gland (Bauman et al., 2006). On the other hand, the SCD enzyme acts on 18:0 as a preferred substrate (Ntambi, 1999). Therefore, high scores in factor 5 suggest high activity of the SCD enzyme, which results in high contents of 14:1 $c 9$ and 16:1 $c 9$, and a low content of 18:0 in milk fat.

The sixth latent factor was named short-chain FA because it was positively correlated with the contents of 4:0, 6:0, and 8:0. Chain SFA from 4:0 to 14:0 are also endogenously synthesized in the mammary gland by acetyl-CoA carboxylase and fatty acid synthase enzymes (Chilliard et al., 2000). Interestingly, FA from 10:0 to 14:0 were associated with factor 1 , suggesting that differences may be present in the endogenous synthesis of even-chain FA according to the carbon chain length. Unlike medium-chain FA (such as from 10:0 to 14:0), short-chain FA may be partly synthesized in the mammary gland by metabolic pathways not dependent on acetyl-CoA carboxylase (Chilliard et al., 2007). With factor analysis, we were able to highlight this metabolic difference by extracting 2 different latent variables, one representing short-chain and one representing mediumchain FA metabolism.

The seventh latent factor was positively associated with the main milk composition traits, such as protein, casein, and fat contents, and was therefore named milk fat protein. The positive association was largely expected because of the well-known positive genetic correlation between fat and protein content in milk (Macciotta et al., 2012).

Latent factor 8 was positively associated with linear odd-chain SFA 11:0, 13:0, and 15:0, and was therefore named odd FA. These FA derive mainly from rumen metabolism, being synthesized by rumen microbes by repeated condensation of malonyl-coenzyme A using propionate as primer (Vlaeminck et al., 2006), abundant in rumen when diets are rich in nonstructural carbohydrates. Moreover, milk linear odd-chain FA are also partially synthesized in the mammary gland, as previously reported by Vlaeminck et al. (2006). This double origin of odd-chain FA and dietary effects may help to explain why factor analysis yielded 2 different latent factors for odd-and branched-chain FA. Interestingly, 17:0 was associated with factor 1 together with its desaturation product (17:1 c9; Fievez et al., 2003). This suggests that the metabolic role of 17:0 in milk fat secretion differs from the other odd-chain FA, probably due to its affinity with the SCD enzyme (Palmquist et al., 2004; Vlaeminck et al., 2006).

The relationship between the SCD enzyme and 18:1 $t 11$ was found in the ninth latent factor (named CLA). It was positively associated with $18: 1 \mathrm{t} 11$ and its mammary desaturation product, 18:2 $c 9, t 11$. Several studies have shown that more than $80 \%$ of milk $18: 2 \quad c 9, t 11$ is due to mammary desaturation of $18: 1 \mathrm{t} 11$, which derives from rumen biohydrogenation of dietary PUFA (Shingfield et al., 2013). Interestingly, the products of SCD were associated with 3 different latent factors: the first de novo FA (17:1 $c 9$, and 18:1 $c 9)$, the fifth desaturation FA $(10: 1 c 9,14: 1 c 9$, and 16:1 $c 9)$, and the ninth CLA $(18: 2 c 9, t 11)$. This suggests that chain length and the unsaturation degree of the substrate could influence the activity of the SCD enzyme.

The last 3 latent factors explained less than $10 \%$ of total variance and 2 of them were related to a single FA. The 10th latent factor, linolenic, was associated with 18:3 $c 9, c 12, c 15$ ( $\alpha$-linolenic acid), whereas the 12 th, vaccelenic, was associated with an intermediate of the rumen biohydrogenation process of $\alpha$-linolenic acid, 18:2 t11,c15 (Shingfield et al., 2013). It is worth pointing out that $\alpha$-linolenic acid was not associated with either the fourth latent factor long-chain FA, which included the elongation products of $\alpha$-linolenic acid, nor with the vaccelenic factor, which was associated with a product of the biohydrogenation of $\alpha$-linolenic acid. This suggests that the $\alpha$-linolenic acid content in milk fat is independent of the abovementioned metabolic pathways and is likely regulated by other factors.

The 11th latent factor was positively associated with SCC, and negatively with milk lactose content, and was therefore named udder health. It is well known that SCC and milk lactose content are indicators of the health of mammary gland cells (Hamann and Kromker, 1997). This result confirms previous observations with the same sample of Brown Swiss cattle (Macciotta et al., 2012). 
Finally, 5 FA did not show any correlations $\geq 0.60$ with any of the extracted factors. Among these FA, the 16:0 had a relatively large communality value (0.82), which could be ascribed to its pivotal role in several pathways of lipid metabolism. This resulted in a large amount of variance shared with the other FA but no association with a specific factor. As far as the other 4 FA are concerned, 17:0 iso (communality 0.52) was, as previously seen, positively associated (0.50) with the branched-chain FA-MY; 20:0 and 16:1t9 both had a communality value of 0.60 but with small associations with several latent factors; finally, only 18:1 t15 $+c 11$ had a very low communality value $(0.31)$, perhaps because of co-elution problems in the analysis.

\section{Effect of Herd/Date on the Latent Factors}

The first important result of the mixed model analysis of factor scores (Table 4) concerns the very large differences in the contribution $\left(\mathrm{r}_{\text {HTD }}^{2}\right)$ of the herd-date (within dairy system and season) variance on total variance ( 8 to $57 \%$ ). The $\mathrm{r}_{\text {HTD }}^{2}$ was $18 \%$ for the milk fat protein factor and $8 \%$ for udder health (i.e., those latent variables related to other milk components than FA). In a study carried out on the same data set, the $\mathrm{r}_{\text {HTD }}^{2}$ was $19 \%$ for fat and $22 \%$ for protein contents, and $12 \%$ for SCS (Bittante et al., 2013). Other experiments, reviewed by Bittante et al. (2012), found the incidence of herd variance on total variance to be about $30 \%$ for milk fat and protein, and less than $10 \%$ for SCS, data that are consistent with our results. Moreover, the branched FA-MY factor had an $\mathrm{r}_{\mathrm{HTD}}^{2}$ of $44 \%$ on total variance, which is basically identical to the value obtained for MY alone (45\%) and close to the values estimated for individual branched FA (45 to 63\%) in the same data set (Pegolo et al., 2016).

The lowest incidence of herd/date variance (9\%) was estimated for the desaturation factor. Pegolo et al. (2016) found the $\mathrm{r}_{\text {HTD }}^{2}$ of individual FA included in this factor to range between 18 and $21 \%$, with the exception of 10:1 c9 (33\%), whereas Stoop et al. (2008) found an estimated value of $19 \%$ for 18:0 obtained from 1,918 milk samples of Dutch Holstein-Friesian cows. This low variability among different herds and sampling dates is likely due to the high degree of genetic control over these FA exerted by the SCD in the mammary gland (Bauman et al., 2006).

The de novo (21\%), vaccelenic $(21 \%)$, and odd FA $(30 \%)$ factors exhibited intermediate $\mathrm{r}_{\text {HTD }}^{2}$. Values for the 11 individual FA given in Pegolo et al. (2016) varied from 18 to 30\%. Exceptions were 11:0, 15:0, and 17:0, which had larger values. Stoop et al. (2008) also found similar values for the 5 even FA, which we found to be the major determinants of the de novo factor.

It could be argued that there should not be large variations between different herds in the most abundant FA in milk fat, such as the major FA characterizing the de novo factor, whereas the largest differences would be expected in minor FA contents. In fact, the factors with the highest incidence of herd/date were CLA (42\%), linolenic (47\%), short-chain FA (49\%), long-chain FA (57\%), and biohydrogenation (57\%; i.e., those related to FA representing small proportions of milk fat). With only 2 exceptions (8:0 and 22:0), the values obtained for the 18 individual FA represented in these factors were quite large (39 to $67 \%$; Pegolo et al.,

Table 4. Analysis of variance ( $F$ - and $P$-values) of the12 extracted factors

\begin{tabular}{|c|c|c|c|c|c|c|}
\hline Item & $\begin{array}{c}\text { Dairy system } \\
F \text {-value }\end{array}$ & $\begin{array}{l}\text { Season } \\
F \text {-value }\end{array}$ & $\begin{array}{c}\text { Herd/Date } \\
\text { He. } \%\end{array}$ & $\begin{array}{l}\text { Parity } \\
F \text {-value }\end{array}$ & $\begin{array}{c}\text { DIM } \\
F \text {-value }\end{array}$ & $\begin{array}{l}\text { Residual } \\
\text { RMSE }^{2}\end{array}$ \\
\hline df & 3 & 1 & 80 & 3 & 10 & - \\
\hline $\mathrm{F} 1^{3}:$ De novo FA & $4.00^{*}$ & 0.75 & 21 & $7.43^{* * *}$ & $30.95^{* * *}$ & 0.79 \\
\hline F2: $\mathrm{MY}^{4}$-branched FA & $20.68^{* * *}$ & $4.39^{*}$ & 44 & $9.04^{* * *}$ & $27.94^{* * *}$ & 0.61 \\
\hline F3: Biohydrogenation & 2.01 & $4.33^{*}$ & 57 & $6.95^{* * *}$ & $2.64^{* *}$ & 0.63 \\
\hline F4: Long-chain FA & 1.05 & 1.22 & 57 & $5.98^{* * *}$ & $2.64^{* *}$ & 0.65 \\
\hline F5: Desaturation & 0.05 & $24.00 * * *$ & 9 & $8.71 * * *$ & $20.90 * * *$ & 0.86 \\
\hline F6: Short-chain FA & 1.79 & 0.21 & 49 & 0.98 & $10.31^{* * *}$ & 0.69 \\
\hline F7: Milk fat protein & $4.03^{*}$ & $11.07 * *$ & 18 & $16.07^{* * *}$ & $62.62^{* * *}$ & 0.72 \\
\hline F8: Odd FA & 1.38 & 0.01 & 30 & 1.91 & $1.93^{*}$ & 0.82 \\
\hline F9: CLA & $9.81^{* * *}$ & $6.40^{*}$ & 42 & $12.77^{* * *}$ & 1.25 & 0.69 \\
\hline F10: Linolenic & $5.53^{* *}$ & $4.69^{*}$ & 47 & 0.76 & $4.86^{* * *}$ & 0.68 \\
\hline F11: Udder health & 0.43 & 0.23 & 8 & $23.31^{* * *}$ & $4.43^{* * *}$ & 0.92 \\
\hline F12: Vaccelenic & 2.12 & $10.89^{* *}$ & 21 & $2.67^{*}$ & 0.93 & 0.86 \\
\hline
\end{tabular}

${ }^{1}$ The variance of herd/date within dairy system and season is expressed as ratio with total variance (herd plus residual).

${ }^{2} \mathrm{RMSE}=$ root mean square error.

${ }^{3} \mathrm{~F}=$ factor.

${ }^{4} \mathrm{MY}=$ milk yield.

${ }^{*} P<0.05 ;{ }^{* *} P<0.01 ;{ }^{* * *} P<0.001$. 
Table 5. Effects of the dairy system, the feed distribution techniques within modern farms, and the moisture source of TMR on the 12 extracted latent factors

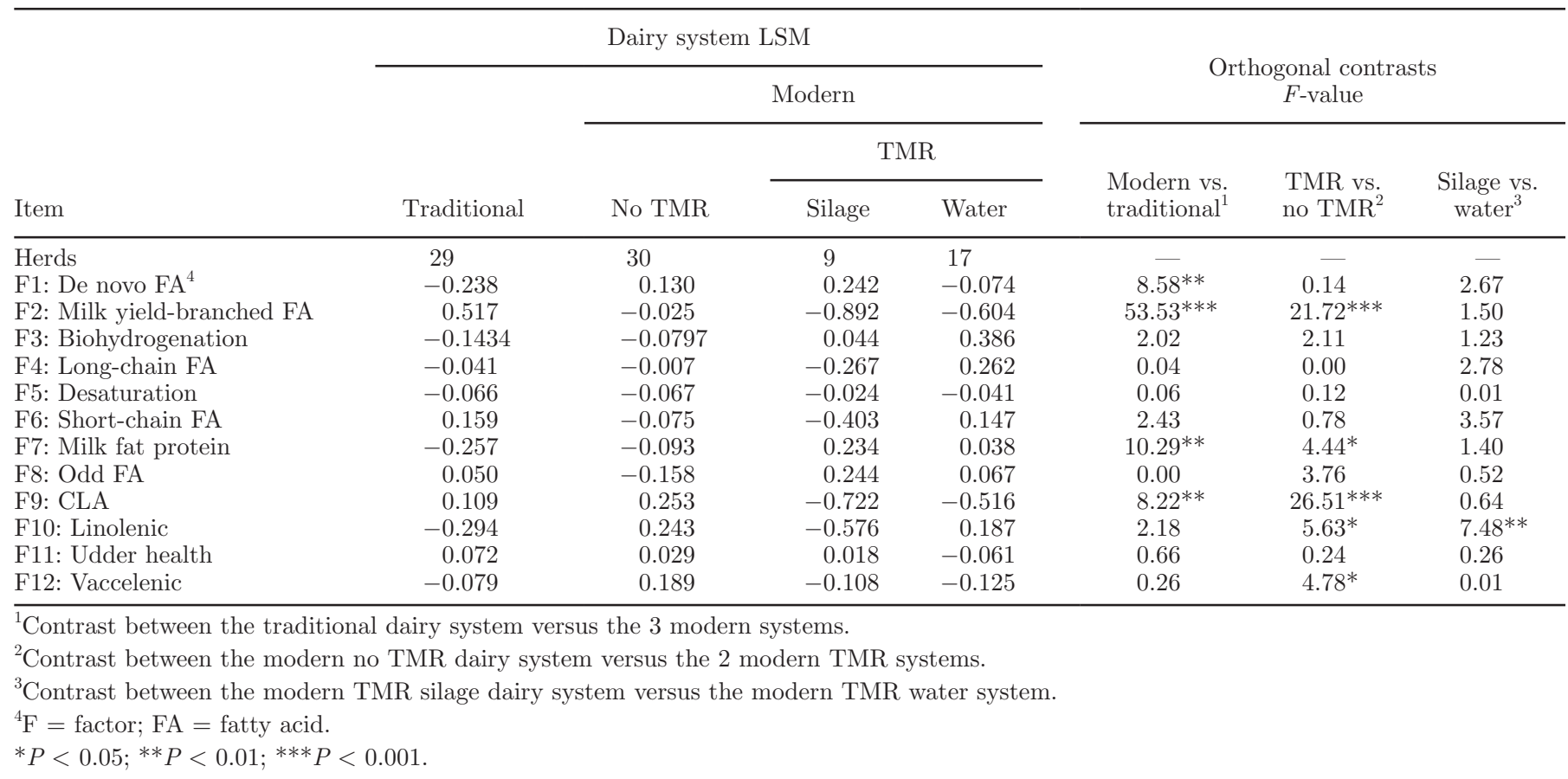

2016). In their study, Stoop et al. (2008) reported very high values for $6 \mathrm{FA}$ (49 to $64 \%)$. The only important discrepancy between the 2 data sets was the very low values (16 to $20 \%$ ) found in the Dutch study for the 3 very short FA (4:0, 6:0, and 8:0) that characterize the short-chain FA factor of the present study, where a large $r_{\text {HTD }}^{2}$ value was found (49\%).

\section{Effects of Dairy System on the Extracted Factor Scores}

Dairy system affected the scores of 5 of the 12 latent factors, whereas season of sampling affected 6 . The least squares means and orthogonal contrasts among the 4 dairy systems examined are given in Table 5 . Dairy systems were primarily associated with factors describing the quantity (branched FA-MY) and quality (milk fat protein) of the milk produced.

On average, cows reared in modern systems produced more milk (26.4 vs. $20.9 \mathrm{~kg} / \mathrm{d}$ ), with higher fat (4.43 vs. $4.19 \%)$ and protein (3.80 vs. $3.65 \%$ ) contents than cows from traditional systems, confirming the findings of a parallel paper by Bittante et al. (2015). The modern systems also had higher scores for the de novo FA and smaller scores for the CLA factors than the traditional system. Previous studies have reported a positive association between the forage:concentrate ratio and branched FA and CLA contents in milk fat (Chilliard and Ferlay, 2004; Vlaeminck et al., 2006), so the lower scores for the branched FA-MY and CLA factors in modern dairy systems compared with the traditional system may be interpreted as being due to the lower amounts of forage they use.

Within the modern dairy systems, the use of TMR was associated with greater MY $(+10 \%)$, and fat $(+5 \%)$ and protein $(+2 \%)$ contents than no TMR, which was reflected in higher scores for the milk fat protein factor and lower scores for the branched FA-low MY factor. This is consistent with the expectation that cows fed TMR commonly present a greater DMI and MY than those on other feeding systems (Bargo et al., 2002). Interestingly, the use of TMR was also associated with low scores for CLA, linolenic, and vaccelenic factors. Because lipid supplements were used in scant quantities on the farms included in the present survey, differences in the concentrations of these FA in the milk might be due to the PUFA content of the kind of forage on which a given feed is based. The presence of silage in the TMR was associated with minor effects on the FA profile, but smaller scores for the linolenic acid factor compared with TMR moistened with water. This pattern confirms that milk 18:3 $c 9, c 12, c 15$ concentration increases with increasing proportions of hay in the traditional diets, and decreases with the inclusion of corn silage in TMR, as previously reported by Coppa et al. (2013). 


\section{Effects of Parity and DIM on the Extracted Factor Scores}

The most significant effect of parity regarded the de novo latent factor, as the score for the primiparous cows was markedly smaller $(P<0.01)$ than the scores for greater parities (Figure 1). Parity significantly affected $(P<0.01)$ the scores of almost all the latent factors, with the exception of the short-chain FA, odd FA, and linoleic factors. With increasing lactations, therefore, the scores for the desaturation and udder health factors increased, whereas the scores for the branched FA-low MY, biohydrogenation, long-chain FA, milk fat protein, CLA, and vaccelenic FA factors decreased. The contribution of lipids mobilized from body depots on milk fat yield can be regarded as greater in primiparous than in pluriparous cows, a point consistently reflected in variations in the latent factors related to lipid mobilization [18:0 (desaturation), 18:1 c9 (de novo FA)], dietary FA (long-chain FA and biohydrogenation), and negative energy balance (i.e., the de novo factor). In this regard, Barber et al. (1997) and Van Haelst et al. (2008) pointed to high lipolysis (i.e., the cow in negative energy balance) being associated with greater proportions of 18:0 and 18:1 $c 9$, and a lower proportion of de novo FA in milk fat. These results suggest that MFA of milk FA could be a tool for summarizing a large number of variables in a few pieces of relevant information with biological meanings.

Days in milk had a significant effect on the large majority of latent factors (Table 4). In particular, scores of factors associated with FA derived from mammary enzymes (de novo FA, desaturation, and long-chain FA) increased during lactation (Figure 2). This pattern may be explained by upregulation of the expression of genes associated with FA uptake from blood (FA synthase, stearoyl Co-A desaturase, and FA elongase) that occurs at the onset of lactation (Loor, 2010). Branched FA-low MY, and biohydrogenation factors also showed a rising trend during lactation, probably due to changes in DMI and diet composition to achieve the nutrient requirements of cows during lactation. At the beginning of lactation, around production peak, feed is usually high in starch (concentrate) because of the need to ensure an adequate energy supply to the cow. Because the branched FA content of milk fat is associated with the

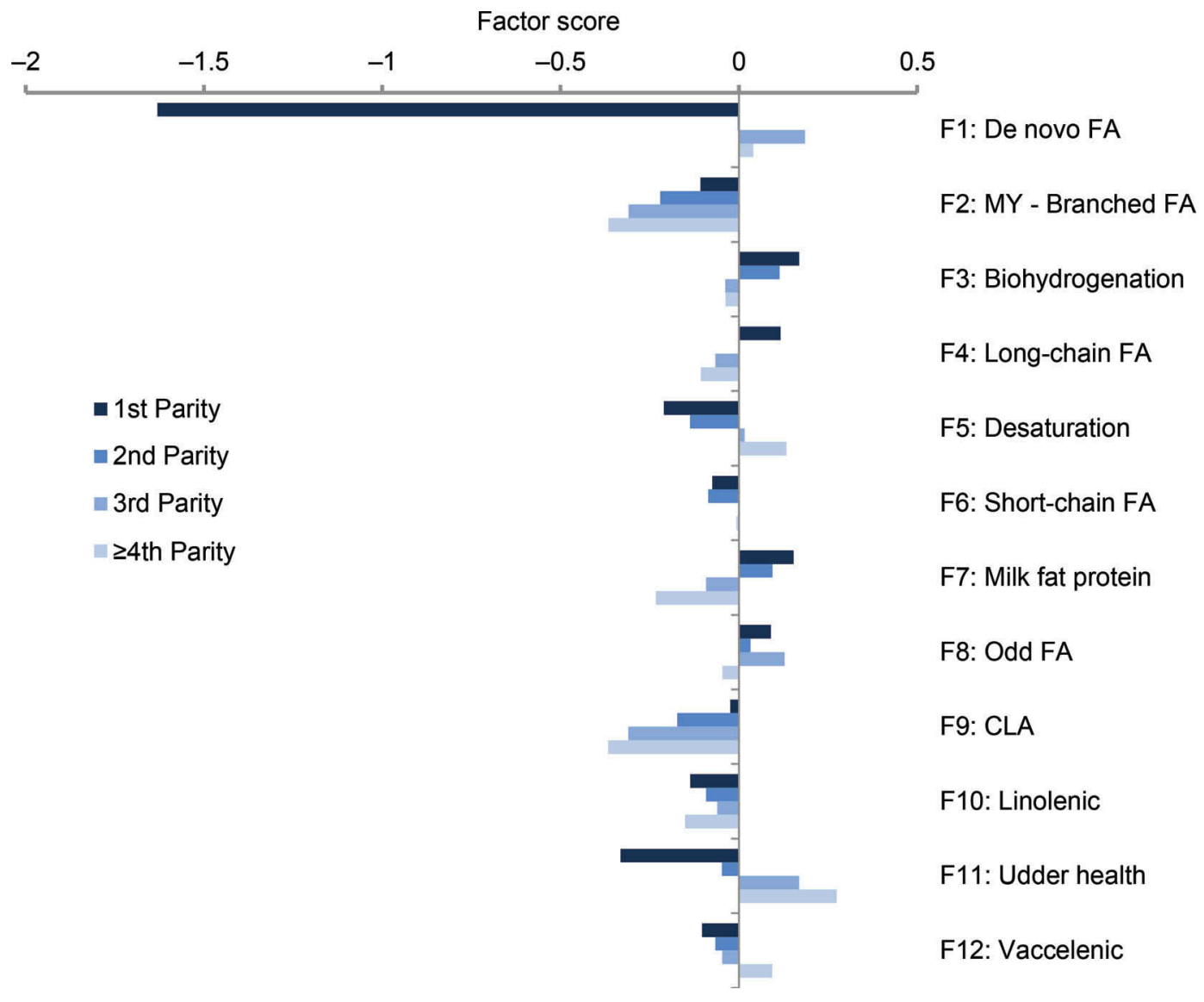

Figure 1. Effect of parity of cows on pattern of milk fatty acid (FA) factors; MY = milk yield. Color version available online. 


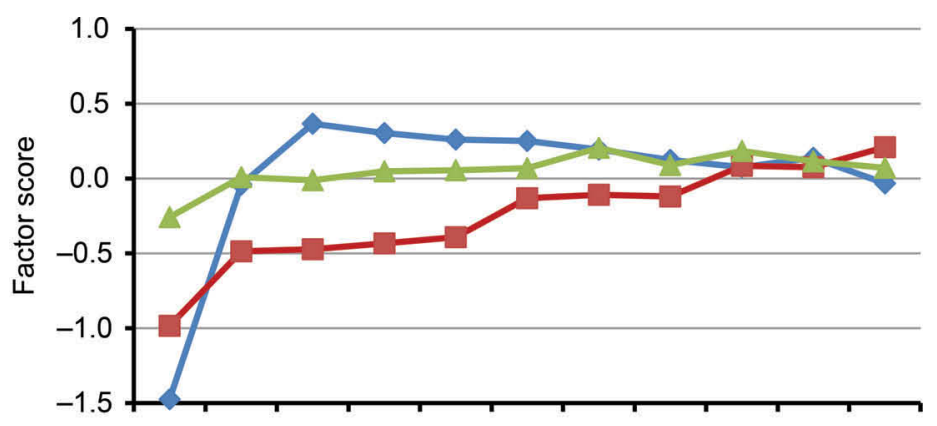

\section{$\leadsto$ De novo FA \\ - Branched FA-Low Milk yield \\ $\rightarrow-$ Biohydrogenation}

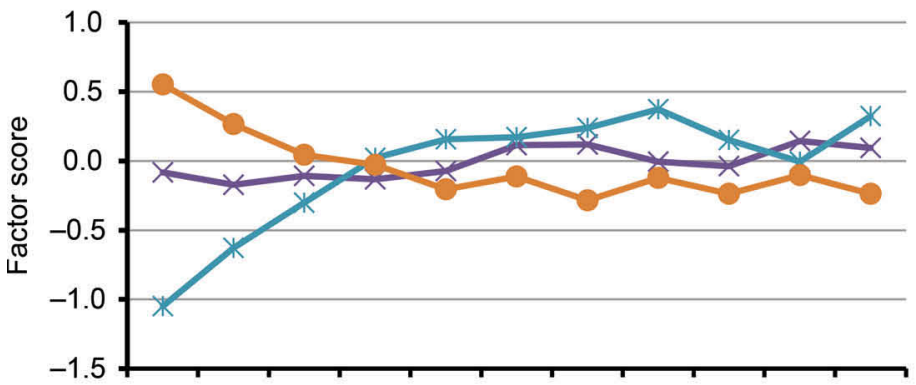

$\leftarrow$ Long chain FA

*-Desaturation

- Short chain FA

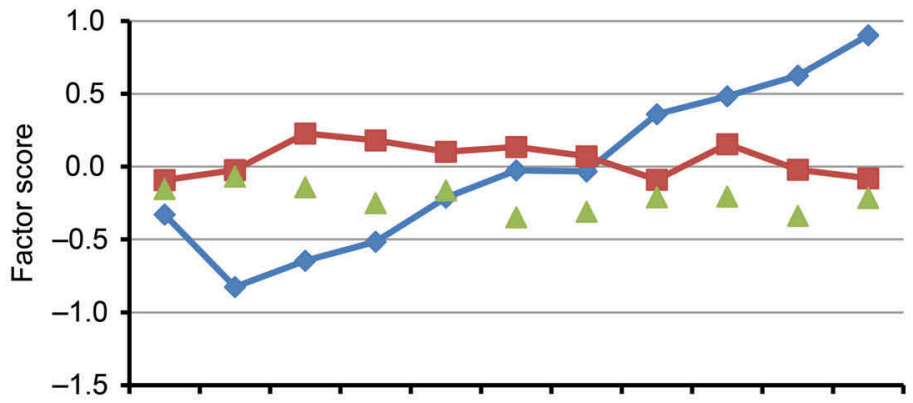

$$
\begin{aligned}
& - \text { Milk fat protein } \\
& - \text { Odds FA } \\
& \triangle \text { CLA }
\end{aligned}
$$
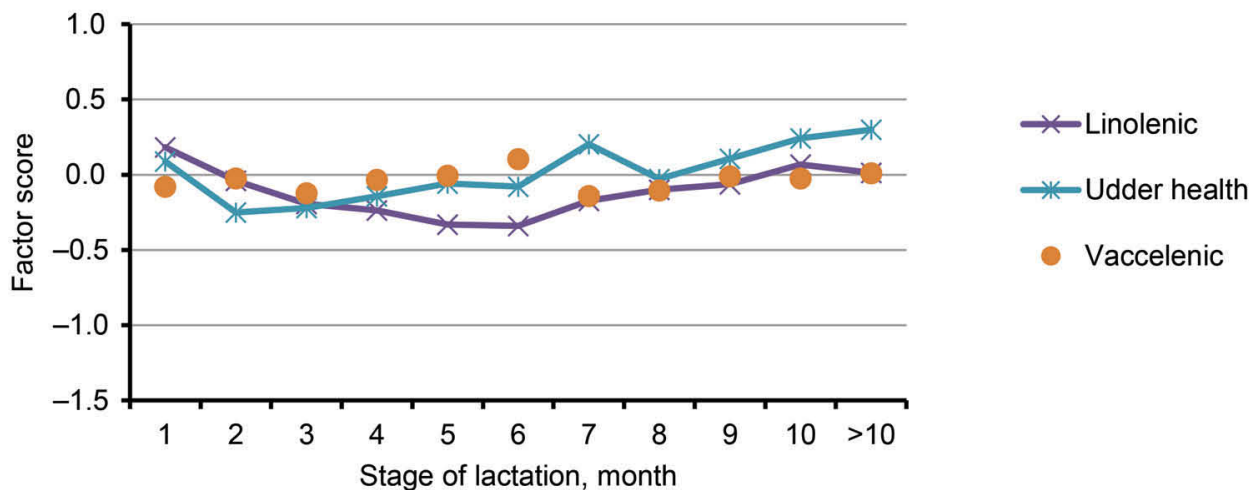

Figure 2. Effect of stage of lactation (month) on pattern of milk fatty acid (FA) factors. The effect was not significant for CLA and vaccelenic factors. Color version available online.

amount of forage in the ration (Vlaeminck et al., 2006), the scores for the branched FA-MY factor tended to increase during lactation, along with a decrease in MY after the peak and the corresponding changes in DMI and proportions of forages included in the ration.

Here, too, the trends of 12 latent factors extracted by MFA were consistent with expectations based on current knowledge of the physiological changes occurring during lactation. We therefore suggest this kind of analysis might be a tool to summarize the most important physiological and metabolic changes taking place in cows within and across lactations in a few latent but explanatory variables obtained from measures of lactation performance and the milk FA profile. 


\section{CONCLUSIONS}

The MFA approach used in this paper had many positive outcomes when applied to a large data set. A first positive outcome concerned the reduction of a great number of variables to a few latent factors with biological meaning. The statistical approach separated groups of FA with similar origins and functions reflecting common or related metabolic pathways. The scores for these latent factors were consistently found to be influenced by different productive environments and individual animal factors, in agreement with current knowledge. This approach therefore represents a valuable tool for studying the effects of different production systems, feeding regimens, and health status on the characteristics of the milk fat, and for identifying strategies for manipulating the milk FA profile in accordance with consumer demand. The inherent nutritional and metabolic information reflected in the milk FA profile could be exploited by taking this approach.

\section{ACKNOWLEDGMENTS}

This research was supported by the University of Padova (CPDA 114230/11). The authors acknowledge the Superbrown Consortium of Bolzano and Trento (Trento, Italy) for the support in sampling and recording activities.

\section{REFERENCES}

Barber, M. C., R. A. Clegg, M. T. Travers, and R. G. Vernon. 1997. Lipid metabolism in the lactating mammary gland. Biochim. Biophys. Acta 1347:101-126.

Bargo, F., L. D. Muller, J. E. Delahoy, and T. W. Cassidy. 2002. Performance of high producing dairy cows with three different feeding ystems combining pasture and total mixed rations. J. Dairy Sci. 85:2948-2963.

Bauman, D. E., I. H. Mather, R. J. Wall, and A. L. Lock. 2006. Major Advances Associated with the Biosynthesis of Milk. J. Dairy Sci. $89: 1235-1243$.

Bionaz, M., and J. J. Loor. 2008. Gene networks driving bovine milk synthesis during the lactation cycle. BMC Genomics 9:366-387.

Bittante, G., A. Cecchinato, N. Cologna, M. Penasa, F. Tiezzi, and M. De Marchi. 2011. Factors affecting the incidence of first-quality wheels of Trentingrana cheese. J. Dairy Sci. 94:3700-3707.

Bittante, G., C. Cipolat-Gotet, and A. Cecchinato. 2013. Genetic parameters of different measures of cheese yield and milk nutrient recovery from an individual model cheese-manufacturing process. J. Dairy Sci. 96:7966-7979.

Bittante, G., C. Cipolat-Gotet, F. Malchiodi, E. Sturaro, F. Tagliapietra, S. Schiavon, and A. Cecchinato. 2015. Effect of dairy farming system, herd, season, parity, and days in milk on modeling of the coagulation, curd firming, and syneresis of bovine milk. J. Dairy Sci. 98:2759-2774.

Bittante, G., M. Penasa, and A. Cecchinato. 2012. Invited review: Genetics and modeling of milk coagulation properties. J. Dairy Sci. 95:6843-6870.

Borreani, G., M. Coppa, A. Revello-Chion, L. Comino, D. Giaccone, A. Ferlay, and E. Tabacco. 2013. Effect of different feeding strategies in intensive dairy farming systems on milk fatty acid profiles, and implications on feeding costs in Italy. J. Dairy Sci. 96:6840-6855.

Chilliard, Y., and A. Ferlay. 2004. Dietary lipids and forages interactions on cow and goat milk fatty acid composition and sensory properties. Reprod. Nutr. Dev. 44:467-492.

Chilliard, Y., A. Ferlay, R. M. Mansbridge, and M. Doreau. 2000 Ruminant milk fat plasticity: Nutritional control of saturated, polyunsaturated, trans and conjugated fatty acids. Ann. Zootech. 49:181-205.

Chilliard, Y., F. Glasser, A. Ferlay, L. Bernard, J. Rouel, and M. Doreau. 2007. Diet, rumen biohydrogenation and nutritional quality of cow and goat milk fat. Eur. J. Lipid Sci. Technol. 109:828855.

Coppa, M., A. Ferlay, C. Chassaing, C. Agabriel, F. Glasser, Y Chilliard, G. Borreani, R. Barcarolo, T. Baars, D. Kusche, O. M. Harstad, J. Verbič, J. Golecký, and B. Martin. 2013. Prediction of bulk milk fatty acid composition based on farming practices collected through on-farm surveys. J. Dairy Sci. 96:4197-4211.

Couvreur, S., C. Hurtaud, C. Lopez, L. Delaby, and L. Peyraud. 2006. The linear relationship between the proportion of fresh grass in the cow diet, milk fatty acid composition and butter properties. J. Dairy Sci. 89:1956-1969.

Delmonte, P., A. R. Fardin-Kia, J. K. G. Kramer, M. M. Mossoba, L. Sidisky, C. Tyburczy, and J. I. Rader. 2012. Evaluation of highly polar ionic liquid gas chromatographic column for the determination of the fatty acids in milk fat. J. Chromatogr. A 1233:137-146.

Feng, S., A. L. Lock, and P. C. Garnsworthy. 2004. A rapid lipid separation method for determining fatty acid composition of milk. J. Dairy Sci. 87:3785-3788.

Fievez, V., E. Colman, J. C. Montoya, I. Stefanov, and B. Vlaeminck. 2012. Milk odd- and branched-chain fatty acids as biomarkers of rumen function: An update. Anim. Feed Sci. Technol. 172:51-65.

Fievez, V., B. Vlaeminck, M. S. Dhanoa, and R. J. Dewhurst. 2003 Use of principal component analysis to investigate the origin of heptadecenoic and conjugated linoleic acids in milk. J. Dairy Sci. 86:4047-4053.

Hamann, J., and V. Kromker. 1997. Potential of specific milk composition variables for cow health management. Livest. Prod. Sci. 48:201-208

Jensen, R. G. 2002. The composition of bovine milk lipids: January 1995 to December 2000. J. Dairy Sci. 85:295-350.

Kramer, J. K., M. Hernandez, C. Cruz-Hernandez, J. Kraft, and M. E. Dugan. 2008. Combining results of two GC separations partly achieves determination of all cis and trans 16:1, 18:1, 18:2 and 18:3 except CLA isomers of milk fat as demonstrated using Ag-ion SPE fractionation. Lipids 43:259-273.

Loften, J. R., J. G. Linn, J. K. Drackley, T. C. Jenkins, C. G. Soderholm, and A. F. Kertz. 2014. Invited review: Palmitic and stearic acid metabolism in lactating dairy cows. J. Dairy Sci. 97:46614674.

Loor, J. J. 2010. Genomics of metabolic adaptations in the peripartal cow. Animal 4:1110-1139.

Macciotta, N. P. P., A. Cecchinato, M. Mele, and G. Bittante. 2012. Use of multivariate factor analysis to define new indicator variables for milk composition and coagulation properties in Brown Swiss cows. J. Dairy Sci. 95:7346-7354.

Macciotta, N. P. P., C. Dimauro, D. J. Null, G. Gaspa, M. Cellesi, and J. B. Cole. 2015. Dissection of genomic correlation matrices of US Holsteins using multivariate factor analysis. J. Anim. Breed. Genet. 132:9-20.

Macciotta, N. P. P., D. Vicario, C. Dimauro, and A. Cappio-Borlino. 2004. A multivariate approach to modelling shapes of individual lactation curves in cattle. J. Dairy Sci. 87:1092-1098.

Mele, M. 2009. Designing milk fat to improve healthfulness and functional properties of dairy products: From feeding strategies to a genetic approach. Ital. J. Anim. Sci. 8:365-373.

Mele, M., A. Serra, A. Buccioni, G. Conte, A. Pollicardo, and P. Secchiari. 2008. Effect of soybean oil supplementation on milk fatty acid composition from Saanen goats fed diets with different forage:concentrate ratios. Ital. J. Anim. Sci. 7:297-311. 
Morrison, F. 1976. Multivariate Statistical Methods. McGraw-Hill, New York, NY.

Ntambi, J. M. 1999. Regulation of stearoyl-CoA desaturase by polyunsaturated fatty acids and cholesterol. J. Lipid Res. 40:1549-1558.

Palmquist, D. L., N. St-Pierre, and K. E. McClure. 2004. Tissue fatty acid profiles can be used to quantify endogenous rumenic acid synthesis in lambs. J. Nutr. 134:2407-2414.

Pegolo, S., A. Cecchinato, J. Casellas, G. Conte, M. Mele, S. Schiavon, and G. Bittante. 2016. Genetic and environmental relationships of detailed milk fatty acids profile determined by gas chromatography in Brown Swiss cows. J. Dairy Sci. 99:1315-1330.

Shingfield, K. J., L. Bernard, C. Leroux, and Y. Chilliard. 2010. Role of trans fatty acids in the nutritional regulation of mammary lipogenesis in ruminants. Animal 4:1140-1166.

Shingfield, K. J., M. Bonnet, and N. D. Scollan. 2013. Recent developments in altering the fatty acid composition of ruminant-derived foods. Animal 7:132-162.

Stoop, W. M., J. A. van Arendonk, J. M. Heck, H. J. van Valenberg, and H. Bovenhuis. 2008. Genetic parameters for major milk fatty acids and milk production traits of Dutch Holstein-Friesians. J. Dairy Sci. 91:385-394.
Sturaro, E., G. Cocca, L. Gallo, M. Mrad, and M. Ramanzin. 2009. Livestock systems and farming styles in Eastern Italian Alps: An on-farm survey. Ital. J. Anim. Sci. 8:541-554.

Sturaro, E., E. Marchiori, G. Cocca, M. Penasa, M. Ramanzin, and G. Bittante. 2013. Dairy systems in mountainous areas: Farm animal biodiversity, milk production and destination, and land use. Livest. Sci. 158:157-168.

Todaro, M., M. Scatassa, and P. Giaccone. 2005. Multivariate factor analysis of Girgentana goat milk composition. Ital. J. Anim. Sci. 4:403-410.

Van Haelst, Y. N. T., A. Beeckman, A. T. M. Van Knegsel, and V. Fievez. 2008. Short communication: Elevated concentrations of oleic acid and long-chain fatty acids in milk fat of multiparous subclinical ketotic cows. J. Dairy Sci. 91:4683-4686.

Vlaeminck, B., V. Fievez, S. Tamminga, R. J. Dewhurst, A. van Vuuren, D. De Brabander, and D. Demeyer. 2006. Milk odd and branched chain fatty acids in relation to the rumen fermentation pattern. J. Dairy Sci. 89:3954-3964. 